\begin{tabular}{|c|c|c|}
\hline \multirow[t]{2}{*}{7} & $\begin{array}{l}\text { International Journal of Current Research in } \\
\text { Biosciences and Plant Biology }\end{array}$ & \\
\hline & Volume $4 \bullet$ Number 2 (February-2017) • ISSN: 2349-8080 (Online) & \\
\hline $\begin{array}{l}\text { EXCELLENI } \\
\text { PUBLISHERS }\end{array}$ & Journal homepage: www.ijcrbp.com & rman juctopecom \\
\hline
\end{tabular}

\title{
Effect of Coenzyme Q 10 on Blood Glucose Level in Streptozotocin Induced Diabetic Rats
}

\author{
Umashanker Prasad Keshri $^{1 *}$, Sonu Kumar ${ }^{2}$ and Manju Gari ${ }^{3}$ \\ ${ }^{I}$ Associate Professor, ${ }^{2}$ PG Student and ${ }^{3}$ Professor and Head, Department of Pharmacology, Rajendra Institute of Medical \\ Sciences, Ranchi, Jharkhand, India \\ *Corresponding author.
}

\begin{abstract}
Coenzyme Q-10 which is lipid-soluble, vitamin-like substance and are present in most eukaryotic cells, primarily in the mitochondria is a component of the electron transport chain and participates in aerobic cellular respiration. The capacity of this molecule to exist in a completely oxidized form and a completely reduced form enables it to perform its functions in the electron transport chain and as an antioxidant respectively. Hyperglycemia in DM generates free radicals by mechanisms that are thought to involve metal catalyzed oxidation of glucose, oxidative degeneration and protein glycation. The presence of free radicals may account for diabetes and its complication. On this background the plan of this research work was made. Healthy male Wistar rats weighing between 150-250 grams were divided in four groups containing six animals in each group. Normal and diabetic animals were treated by placebo and coenzyme Q10 $1.8 \mathrm{mg} / \mathrm{kg}$ body weight respectively and investigated for fasting blood glucose levels. Blood glucose level in diabetic rats was significantly decreased in three weeks period. Therefore we can conclude that Coenzyme Q10 reduces the fasting blood sugar level in streptozotocin induced diabetic rats and it is of statistical significance in long term use (at 21 days and later).
\end{abstract}

\section{Introduction}

Diabetes mellitus is a metabolic syndrome characterized by chronic hyperglycemia with disturbance of carbohydrate, fat and protein metabolism resulting from defects in insulin secretion, insulin action, or both (Danaei et al., 2011). Several distinct types of Diabetes mellitus are caused by a complex interaction of genetics and environmental factors. Diabetes is renowned as 'silent epidemic'. The slow progression and lack of symptoms in early stages of the disease preclude seeking medical attention and preventive care.

\section{Article Info}

Accepted: 25 January 2017

Available Online: 06 February 2017

\section{Keywords}

Blood glucose level

Coenzyme Q10

Diabetic rats 
and a completely reduced form enables it to perform its functions in the electron transport chain and as an antioxidant respectively (Shindo et al., 1994).

There are two major factors that lead to deficiency of Coenzyme $\mathrm{Q}-10.1^{\text {st }}$ is the reduced biosynthesis, and $2^{\text {nd }}$ is its increased utilization by the body (Hyson et al., 2010). Toxicity is not usually observed with high doses of Coenzyme Q-10 up to $3600 \mathrm{mg}$ per day in healthy as well as unhealthy persons (Hathcock and Shao, 2006). However, some adverse effects like abdominal discomfort, nausea, vomiting, etc. has been observed in very high doses.

Hyperglycemia in DM generates free radicals by mechanism that is thought to involve metal catalyzed oxidation of glucose, oxidative degeneration and protein glycation (Wolff and Dean, 1987). Recurrent high blood glucose concentration degenerates vital tissues and it is correlated with diabetes and its complications. Therefore chronic antioxidant therapy may be useful in decreasing the risk of diabetes and its complications. Coenzyme Q10 is an antioxidant, scavenges free radicals directly, inhibits biomolecule oxidation, regulates oxidative phosphorylation and prevents lipid per oxidation (Modi et al., 2006) that's why Coenzyme Q-10 treatment may produce antidiabetic effect. Some research work has been done but the result is confusing. In two randomized trial first done by Henriksen and co-workers in 1999, and second done by Eriksson and co-workers in1999 using 100 and $200 \mathrm{mg}$ of coenzyme Q 10 in patient with type 1 and type 2 diabetes found no difference in glycemic control and insulin requirement. Considering all these facts the proposal of this experiment was made.

\section{Materials and methods}

\section{Animals}

Healthy male Wistar rats weighing about 150-250 g were selected for the present study. The animals were kept in clean and dry cages, with $12 \mathrm{~h}: 12 \mathrm{~h}$ light-dark cycle at room temperature and humidity. They were acclimatized to the available housing conditions and were fed with standard laboratory diet consisting of soaked black gram. Water was given ad libitum. Arrangements were made to ensure regular cleaning of cages and disposal of excreta and urine. The cages were floored with a layer of saw dust for absorption of urine of rats. The whole experiment was conducted in accordance with ethical norms approved by Institutional Animal Ethics Committee (IAEC) Guidelines. Drugs used in this experiment were coenzyme Q10 $20 \mathrm{mg}$, (brand name Tab CoQ, Manufacturing Company: Universal Medicare), tab.metformin $500 \mathrm{mg}$ (glyciphage, franco-Indian pharmaceuticals), Inj. streptozotocin $250 \mathrm{mg}$ powder, Himedia, Mumbai and nicotinamide $100 \mathrm{~g}$ powder, Animed, Kolkata.

\section{Study design}

The experiment was done in "Department of Pharmacology \& Therapeutics, Rajendra Institute of Medical Sciences, Ranchi". The animals used for the study were healthy and active male Wistar rats weighing about 150-250 grams. Only those rats were included in the study whose fasting blood sugar after induction of diabetes was in the range of $200-250 \mathrm{mg} / \mathrm{dl}$.

Experimental animals were divided into four groups having six animals in each group. The groups were as follows 1. Group A; normal control group, treated with $1 \%$ gum acacia, 2.Group B; diabetic control group, streptozotocin induced diabetic rats treated with $1 \%$ gum acacia 3. Group $\mathrm{C}$; non diabetic rats treated with Coenzyme Q10, 1.8mg/kg body weight, 4. Group D; Diabetic Control rats treated with Coenzyme Q10 1.8 $\mathrm{mg} / \mathrm{kg}$ body weight.

All the cages were appropriately labeled. Animals in each cage were also labelled separately and colour coded with the help of permanent marker. Rats were given different treatment orally once daily for 28 days in the morning hour at 09:30-10:30 am.

\section{Induction of diabetes mellitus}

Diabetes was induced by freshly prepared single intraperitoneal injection of streptozotocin in the dose of $60 \mathrm{mg} / \mathrm{kg}$. Just 15 minutes before the streptozotocin injection, nicotinamide was injected intraperitoneally in a dose of $120 \mathrm{mg} / \mathrm{kg}$ (Nayak, 2014). To administer streptozotocin and nicotinamide intraperitoneally, animal was held with its ventrum exposed and head pointed downwards. A 26 gauge needle with $1 \mathrm{ml}$ syringe was inserted into the abdominal cavity in the lower right quadrant to avoid the injury to the caecum and urinary bladder. The needle was directed towards the animal's head at an angle of 15-20 degrees and inserted approximately $5 \mathrm{~mm}$ in depth. Following insertion of needle the drug solutions were gently 
released. After intraperitoneal injections animals were allowed to drink 5\% glucose solution overnight to overcome streptozotocin induced hypoglycemia.

The fasting blood glucose level was determined after 72 hrs of streptozotocin injection. The rats having blood glucose level in the range of $200-250 \mathrm{mg} / \mathrm{dl}$ were used for the study. The diabetic animals were allowed free access to tap water, normal laboratory diet, and were maintained at room temperature in their cages.

Though diabetes was confirmed after $72 \mathrm{hrs}$ of streptozotocin induction, coenzyme Q10 was started on $8^{\text {th }}$ day from induction and this $8^{\text {th }}$ day was considered as day ' 0 '. Then the treatment continued for 28 days. The blood samples were collected from all groups before induction of diabetes, after $72 \mathrm{hrs}$ of diabetic induction as well as on day $0,7,14,21,28$ day to determine the blood glucose level by glucometer.

\section{Statistical analysis}

Statistical analysis of data was carried out by employing analysis of variance. One way ANOVA test was used to compare the effect of drugs on different groups. Tukey's HSD test was used for post-hoc analysis of significant overall differences (Park, 2013).

\section{Results and discussion}

\section{Effect of Coenzyme Q10 on fasting blood sugar level of non diabetic groups}

The fasting blood glucose level in non diabetic and non diabetic coenzyme Q 10 treated groups was in stable range. In coenzyme Q10 treated group no significant decrease in blood sugar level was observed. Animal of this group did not develop hypoglycemia during the experimental period. Coenzyme Q10 has beneficial effects in diabetes and diabetes induced complications
(Modi et al., 2006). So the above mentioned observations are desirable.

\section{Effect of Coenzyme Q10 on fasting blood sugar level in diabetic groups}

Fasting blood sugar of diabetic rats treated by placebo (group B) gradually increased during the study period where as sugar level in group D (treated with coenzyme Q10) showed sequential decrease throughout the study (Table 1). Increase in blood sugar level in streptozotocin induced diabetic rats is expectable due to damage of beta cell. The statistical comparison between Group A and Group C is provided in Table 2. Statistically significant decrease FBS was observed in coenzyme Q 10 treated group on day 21 with $p$-value of 0.001 (Table 3 ). The possible mechanism by which chronic use of Coenzyme Q10 may be beneficial in diabetes is that Coenzyme Q10 works as an electron transporter in ATP synthesis by mitochondria. Coenzyme Q 10 decreases the oxidative stress by converting to a reduced state, scavenging the free radicals. It also regulates oxidative phosphorilation and prevents lipid peroxidation (Bargossi et al., 1994). In this way it prevents further damage of the pancreatic beta cell. This enzyme takes part in the generation of ATP. Those organs which have highest energy requirements such as the heart, liver, pancreas and kidney have the highest Co enzyme Q10 concentrations (Aberg et al., 1992). On day 28, p value was found highly significant that indicates its effects trying to achieving normal physiology probably via reducing the oxidative stress, and above mentioned mechanism (Ernster and Dallner, 1995). Result of this study resembles with the study done by Modi et al. (2006). In a randomized trial Hodgson et al. (2002) found modest improvement in A1C level by this drug in $200 \mathrm{mg}$ dose once daily in 12 weeks period which also support the result achieved in this experiments.

Table 1. Showing sequential changes in FBS in different groups throughout the study period. All the values are expressed as mean \pm standard deviation.

\begin{tabular}{lllll}
\hline & Group A & Group B & Group C & Group D \\
\hline Day 0 & $86.50 \pm 1.87$ & $206.17 \pm 2.71$ & $87.00 \pm 2.10$ & $206.00 \pm 2.19$ \\
Day 7 & $86.83 \pm 1.47$ & $207.33 \pm 3.93$ & $86.67 \pm 2.34$ & $205.33 \pm 1.63$ \\
Day 14 & $87.17 \pm 1.72$ & $208.67 \pm 3.56$ & $84.33 \pm 3.01$ & $203.83 \pm 2.48$ \\
Day 21 & $86.33 \pm 3.01$ & $209.83 \pm 3.92$ & $83.50 \pm 2.66$ & $201.00 \pm 2.83$ \\
Day 28 & $86.67 \pm 2.16$ & $211.17 \pm 3.87$ & $82.67 \pm 2.73$ & $195.67 \pm 2.73$ \\
\hline
\end{tabular}


Table 2. The statistical comparison between Group A and Group C.

\begin{tabular}{llllll}
\hline & Day 0 & Day 7 & Day 14 & Day 21 & Day 28 \\
\hline Group A & $86.50 \pm 1.87$ & $86.83 \pm 1.47$ & $87.17 \pm 1.72$ & $86.33 \pm 3.01$ & $86.67 \pm 2.16$ \\
Group C & $87.00 \pm 2.10$ & $86.67 \pm 2.34$ & $84.33 \pm 3.01$ & $83.50 \pm 2.66$ & $82.67 \pm 2.73$ \\
Mean difference & 0.5000 & 0.1667 & 2.8333 & 2.8334 & 4 \\
$p$-value & 0.998 & 1 & 0.539 & 0.654 & 0.137 \\
\hline
\end{tabular}

Table 3. The statistical comparison between Group B and Group D.

\begin{tabular}{llllll}
\hline & Day 0 & Day 7 & Day 14 & Day 21 & Day 28 \\
\hline Group B & $206.17 \pm 2.71$ & $207.33 \pm 3.93$ & $208.67 \pm 3.56$ & $209.83 \pm 3.92$ & $211.17 \pm 3.87$ \\
Group D & $206.00 \pm 2.19$ & $205.33 \pm 1.63$ & $203.83 \pm 2.48$ & $201.00 \pm 2.83$ & $195.67 \pm 2.73$ \\
Mean difference & 0.1667 & 2 & 4.8333 & 8.8333 & 15.5000 \\
$p$-value & 1 & 0.839 & 0.067 & $0.001 *$ & $0.000^{*}$ \\
\hline
\end{tabular}

\section{Conclusion}

From the results of the present study we can conclude that Coenzyme Q10 reduces the fasting blood sugar level in streptozotocin induced diabetic rats and it is of statistical significance in long term use (at 21 days and later). On the basis of this study we can also comment that Coenzyme Q10 has no hypoglycemic effect on normal rats. It may have supportive role in diabetes. Further more studies are needed to establish it as a novel anti diabetic drug.

\section{Conflict of interest statement}

Authors declare that they have no conflict of interest.

\section{References}

Aberg, F., Appelkvist, EL., Dallner, G., Ernster, L., 199 2. "Distribution and redox state of ubiquinones in rat and, human tissues. Arch. Biochem. Biophys. 295(2), 230.

Bargossi, A. M., Battno, M., Gaddi, A., et al., 1994. Exogenous CoQ10 preserves plasma uboquinone levels in patients treated with 3- hydroxy-3methylglutaryl coenzyme A reductase inhibitors. Int J. Clin. Lab. Res. 24, 171-176.

Danaei, G., Finucane, M. M., Lu, Y., Singh, G.M., Cowan, M. J., Paciorek, C. J., et al., 2011. National, regional, and global trends in fasting plasma glucose and diabetes prevalence since 1980: Systematic analysis of health examination surveys and epidemiological studies with 370 country-years and 2.7 million participants. Lancet. 378(9785), 31-40.

Dutton, P. L., Ohnishi, T., Darrouzet, E., Leonard, M.A.,
Sharp, R.E., Cibney, B.R., Daldal, F., Moser, C.C., 2000. 4 Coenzyme $Q$ oxidation reduction reactions in mitochondrial electron transport. In: Coenzyme Q: Molecular Mechanisms in Health and Sisease (Eds.: Kagan, V.E., Quinn, P.J.). CRC Press, Boca Raton. pp.65-82.

Eriksson, J.G., Forsen, T.J., Mortensen, S.A., Rohde, M., 1999. The effect of coenzyme Q10 administration on metabolic control in patients with type 2 diabetes mellitus. Biofactors. 9, 315-318.

Ernster, L., Dallner, G., 1995. Biochemical, physiological and medical aspects of ubiquinone function. Biochim. Biophys. Acta. 1271(1), 195204.

Hathcock, J.N., Shao, A., 2006. Risk assessment for coenzyme $\mathrm{Q}_{10}$ (Ubiquinone). Regul. Toxicol. Pharmacol. 45(3), 282-288.

Henriksen, J.E., Andersen, C.B., Hother, N.O., Vaag, A., Mortensen, S.A., Beck, N.H., 1999. Impact of ubiquinone (coenzyme Q10) treatment on glycaemic control, insulin requirement and well-being in patients with type 1 diabetes mellitus. Diabet. Med. $16,312-318$.

Hodgson, J. M., Watts, G. F., Playford, D. A., Burke, V., Croft, K. D., 2002. Coenzyme Q10 improves blood pressure and glycaemic control: a controlled trial in subjects with type 2 diabetes. Eur. J. Clin. Nutr. 56, 1137-1142.

Hyson, H. C., Kieburtz, K., Shoulson, I., et al., 2010. Safety and tolerability of high-dosage coenzyme $\mathrm{Q}_{10}$ in Huntington's disease and healthy subjects. Mov. Disord. 25(12), 1924-1928.

Modi, K.P., Vishwakarma, S.L., Goyal, R.K., Bhatt, P.A., 2006. Beneficial effects of coenzyme Q10 in streptozotocin-induced type I diabetic rats. Iranian J. 
Pharmacol. Therapeut. 5, 61-65.

Nayak, Y., Hillemane, V., Daroji, V. K., Jayashree, B. S., Unnikrishnan, M. K., 2014. Antidiabetic activity of benzopyrone analogues in nicotinamidestreptozotocin induced type 2 diabetes in rats. Scient. World J. 2014, Article ID 854267. 12p.

Park, K., 2013. Park Text Book of Preventive and Social Medicine. $20^{\text {th }}$ Edn. 172p.
Shindo, Y., Witt, E., Han, D., Epstein, W., Packer, L., 1994. Enzymic and non-enzymic antioxidants in epidermis and dermis of human skin. J. Investig. Dermatol. 102(1), 122-124.

Wolff, S. P., Dean, R.T., 1987. Glucos autoxidation and protein modification. Thepotential role 'autoxidative glycosylation' in diabetes. Biochem. J. 245, 243250 .

\section{How to cite this article:}

Keshri, U. P., Kumar, S., Gari, M., 2017. Effect of coenzyme Q 10 on blood glucose level in streptozotocin induced diabetic rats. Int. J. Curr. Res. Biosci. Plant Biol. 4(2), 67-71. doi: http://dx.doi.org/10.20546/ijcrbp.2017.402.009 